Volume 29, 2019

http://journals.sfu.ca/cjsdw

\title{
Article
}

\section{Writing Instruction, Academic Labour, and Professional Development}

\author{
Heidi Darroch \\ Camosun College \\ Micaela Maftei \\ Camosun College \\ Sara Humphreys \\ University of Victoria
}

As we envisioned this special section and, in turn, encouraged colleagues to contribute, we confronted one of the ironies of post-secondary writing instruction: many of the people entrusted with the responsibility of supporting student writing development are, essentially, excluded from professional conversations about effective writing pedagogy. That is, hired term-by-term, treated by their departments as fungible, and burdened with excessive teaching loads, university writing instructors may lack a sense of belonging to a profession or a discipline. College instructors, in turn, are also frequently precarious; even if working in full-time and permanent positions, they have little opportunity to engage with the profession, conducting research, as Brenna Clarke Gray points out, "off the sides of our desk." The effect is a feeling of isolation and, for too many, despair about the sustainability of their work in higher education. This sentiment is expressed in the excellent work submitted by our contributors, who are each at differing points on their professional timelines, and, as a result, provide a range of viewpoints. We are grateful for their provocative and engaging work, and we also appreciate and acknowledge the formidable challenges of potential contributors who explained why they could not produce articles for publication--including some who struggled with how to represent their experience of academic precarity without hampering their employment prospects. We thank the editors of $C J S D W / R$ for their patience and assistance as we completed this project amid other responsibilities.

This special section, as our title suggests, deals with the current state of Writing Studies in Canada, from a comparative Canada-U.S. perspective. Our contributors are attentive to the impact 
Volume 29, 2019

http://journals.sfu.ca/cjsdw

of uneven visibility and resourcing in Writing Studies across the country and across different kinds of higher educational institutions. While the behemoth of First-Year Composition in the United States has a lengthy institutional history, writing instruction in Canada is more varied and disparate in location and approach. Roger Graves (1993) has identified rhetoric and belletristic traditions as dominant in the Canadian writing instruction context, pointing out the longstanding tradition of disavowing an "American" approach. This disavowal lacks ethos if the timeline of Canadian and U.S. composition courses is taken into consideration. Indeed, Canada had yet to even accept the idea of the composition class as separate from literary study by the late twentieth century (Johnson, 1988, p. 869). Currently, composition pedagogy in Canada has embraced a more inclusive approach over hegemonic literary practices as universities encourage a wide range of student populations to enroll. Still, Writing Studies fights for recognition in the academy as a discipline (Landry, 2016).

One of the central differences between U.S. and Canadian Writing Studies is in the area of professional development and training, the lack of which leads to institutional invisibility and even the dismissal of Writing Studies as a real discipline in Canada. Pedagogical training and ongoing faculty development have not been evenly available to permanent or sessional instructors of writing. And without immersion in Writing Studies research, many writing instructors have been left to develop their own approaches, with limited preparation time. Periodic efforts at standardization are often imposed within a department or program to address concerns about divergent grading practices or learning outcomes. Opportunities for professional development, even where available, are rarely compensated; most often they are offered in a top-down manner rather than through consultation within learning communities, thus further reflecting the field's inequities.

In different ways, our contributors all echo the central assertion of John Warner's Why They Can't Write (2018): effective writing instruction matters, and the conditions under which writing is taught-from graduate training and professional development to class size and employment security-have a profound impact on students. Even in the U.S. context, where there are multiple graduate programs in rhetoric and composition, Horning argues that insufficient attention is paid to the role of reading in teaching writing; she calls for more extensive professional preparation and development, and outlines students' challenges in critical reading in a range of environments, including online. In Canada, where graduate preparation for writing instruction is more limited, Thieme acknowledges the substantial number of instructors who have not benefited from disciplinary immersion in the field, advocating for comprehensive instructor and student access to 
Volume 29, 2019

http://journals.sfu.ca/cjsdw

writing studies' theoretical concepts. Conversely, Lukas and Personn argue that the range of disciplinary backgrounds of Canadian writing instructors may be a strength and propose teaching argument through the concept of kairos, as a responsive and situated practice. Dunbar reflects on her experience teaching writing in both Canada and the U.S. and articulates a common concern among writing faculty members with heavy teaching loads: is it possible to carry out research in the field when teaching (and often administrative) burdens can be heavy?

While we are certainly gaining ground in Writing Studies, Canada still lacks comprehensive graduate training. Albeit only recently, post-secondary institutions have realized the need for trained faculty in composition and rhetoric, yet few programs exist that prepare graduate students in the field. In addition, there are a limited number of tenure-stream positions in Writing Studies, making the profession both exploitative and unattractive, despite the desperate need for faculty. As Jennifer Clary-Lemon (2009) has observed, broadly speaking, Writing Studies "is struggling to emerge in Canada" (p. 98). The scholars who contributed to this special section (or desired to) are testament to this small, yet determined, growth.

What's also clear in these essays is a desire for more connection between scholars, departments, nations, cultures, and programs. The absence of a sustained network of programs in Canada has given rise to myriad problems, from the myth that anyone can teach writing to the limited awareness, even in the English departments where writing instruction has traditionally been housed, of Writing Studies as a rich and robust discipline. Such myths and misconceptions have caused real and lasting harm to the profession, to faculty, and, perhaps most disturbing, to the students we teach.

Taken together, these papers offer an important look into the realities of writing instruction today, as well as speaking to intentions and possibilities for the future. It is our sincere hope that this special section can spark discussion amongst faculty/within departments and programs, and work to offer representation of the important work being done today, often despite significant challenges, as well as useful and relevant directions for growth/change.

\section{Acknowledgements}

Many thanks to Katja Thieme and Sarah Banting for their contributions to the CASDW panel which instigated this special section. Katja's assistance in selecting articles, and her willingness to share her own work, are also much appreciated 
Volume 29, 2019

http://journals.sfu.ca/cjsdw

\section{References}

Clarke Gray, B. (June 2015). Guest post: College representation and ACCUTE. https://accute.ca/2015/06/18/guest-post-college-representation-and-accute-brenna-clarkegray/

Clary-Lemon, J. (2009). Shifting tradition: Writing research in Canada. American Review of Canadian Studies, 39(2), 94-111. Retrieved from https://doi.org/10.1080/02722010902848128

Graves, R. (1993). Composition in Canadian universities. Written Communication, 10(1), 72-105.

Johnson, N. (1988). Rhetoric and belle lettres in the Canadian academy: An historical analysis. College English, 50 (8). 861-873 Retrieved from https://www.jstor.org/stable/377982

Landry, D. (2016) Writing studies in Canada: A people's history Unpublished doctoral dissertation. University of British Columbia, Vancouver, B.C., Canada. Retrieved from https://doi.org/10.14288/1.0308778

Smith, T. S. (2006). Recent trends in undergraduate writing courses and programs in Canadian universities. In R. Graves \& H. Graves (Eds.), Writing centres, writing seminars, writing culture: Writing instruction in Anglo-Canadian universities (pp. 319-370). Winnipeg, MB, Canada: Inkshed Press.

Warner, J. (2018). Why they can't write: Killing the five-paragraph essay and other necessities. Baltimore, MD, USA: Johns Hopkins UP. 